\title{
Meta-analysis of drug efficacy in adult vs pediatric trials of patients with PGTC seizures
}

Douglas R. Nordli, Jr., MD, Emilia Bagiella, PhD, Alexis Arzimanoglou, MD, Jinping Wang, PhD, Dinesh Kumar, PhD, Antonio Laurenza, MD, and Jacqueline French, MD

Neurology ${ }^{\circledR}$ 2020;94:e1845-e1852. doi:10.1212/WNL.0000000000009325

\author{
Correspondence \\ Dr. Nordli \\ dnordli@ \\ peds.bsd.uchicago.edu
}

\begin{abstract}
Objective

A meta-analysis of published studies was performed to determine whether the efficacy of antiseizure drugs in adults with primary generalized tonic-clonic seizures (PGTCS) is comparable with that in the pediatric population (2-12 years of age).
\end{abstract}

\section{Methods}

Electronic searches were conducted in EMBASE, Medline, and the Cochrane Central Register of Controlled Trials for clinical trials of PGTCS in adults and children 2-12 years of age. Neurologists used standardized search and study evaluations to select eligible trials. Median percent reduction in seizure frequency from baseline and $\geq 50 \%$ responder rates were used to compare drug efficacy in adults and children.

\section{Results}

Among 7 adjunctive-therapy PGTCS trials in adults and children (2-12 years of age) that met evaluation criteria, effect sizes were consistent between adults and children for lamotrigine and topiramate. The baseline-subtracted median percent seizure reduction in seizure frequency ranged from $50.0 \%$ to $79.7 \%$ in children and $57.0 \%$ to $64.0 \%$ in adults. The $\geq 50 \%$ responder rate was similar between children and adults in a topiramate study ( $50 \%$ in children compared with $58 \%$ in adults).

\section{Conclusions}

This meta-analysis supports the use of drug response from antiseizure drug clinical trials for PGTCS in adults to predict comparable treatment response in children 2-12 years of age with PGTCS. 


\section{Glossary}

CI = confidence interval; FOS = focal-onset seizures; $\mathbf{L T G}=$ lamotrigine; $\mathbf{O R}=$ odds ratio; PGTCS = primary generalized tonic-clonic seizures; $\mathbf{S M D}=$ standardized mean difference; $\mathbf{T P M}=$ topiramate.

Primary generalized tonic-clonic seizures (PGTCS) are a debilitating seizure type afflicting adults and children, and are associated with potentially serious consequences including sudden unexpected death in epilepsy. ${ }^{1,2}$ Clinical trials in children present several challenges, particularly when drugs are already approved for use in adults. As a result, children often receive off-label or unlicensed products for which efficacy, safety, and pharmacokinetics have not been established. Recently, antiseizure drug efficacy in adults has been extrapolated to children when the disease course/disorder is similar, ${ }^{3}$ and key differences sometimes emerge when independently studying pharmacokinetics, safety, and tolerance in children. ${ }^{4}$

A 2017 review of clinical trials for focal-onset seizures (FOS) demonstrated comparable percent seizure reduction and responder rates between adults and children (2-18 years of age) for 5 antiseizure drugs, and resulted in approval of extrapolation of efficacy data from adults to children experiencing FOS. ${ }^{5}$ In addition, a review of antiseizure drug development in children concluded no difference in results from large randomized clinical trials in adults and children that used percent seizure reduction from baseline as the efficacy measure, supporting extrapolation of efficacy data from adults to children $\geq 2$ years of age for focal epilepsy. ${ }^{3}$

This analysis evaluates evidence for extrapolating antiseizure drug efficacy data from comparable trials in adults with PGTCS for treatment of pediatric patients (2-12 years of age) with PGTCS, eliminating the need for potentially unfeasible efficacy trials in children.

\section{Methods}

\section{Search strategy, selection criteria, and data abstraction}

The current study was initiated in response to a regulatory request from the Pediatric Committee of the European Medicines Agency as part of regulatory guidance in the pediatric approval process for the antiseizure drug perampanel. Electronic searches of EMBASE, Medline, and the Cochrane Central Register of Controlled Trials were conducted for controlled trials in the treatment of PGTCS published from 1970 to 2015 using predefined criteria (text e-1, doi.org/10. 5061/dryad.cg24gt6). In this meta-analysis, we interpret the term primary generalized tonic-clonic seizures to refer to generalized tonic-clonic seizures that occur in the context of the idiopathic (presumed genetic) generalized epilepsies. In doing so, we also accept that purely generalized tonic-clonic seizures may occur outside of the widely recognized epilepsy syndromes and also that seizures that appear to be generalized at onset may also occur in the context of focal epilepsies, where rapid secondary generalization may occur. The use of this term was meant to restrict the analysis to a more homogeneous population, although in clinical practice we concede this may be difficult to apply in all cases.

The initial online database search for trials on epilepsy and tonicclonic seizures identified 19,485 citations (figure 1). To minimize the risk of bias in individual studies, only publications that presented results from controlled, randomized, double-blind trials were included. Duplicate titles resulting from searches of more than 1 database and slight variations in the entries of titles or authors in the databases were removed. Randomized clinical trials were selected (302) and conference proceedings were excluded. A neurologist (A.L.) and a statistician (J.W.) reviewed 262 unique abstracts by title, key words, and content. Full-text articles were obtained for 39 abstracts for controlled, randomized clinical trials potentially relating to PGTCS. Articles were evaluated by A.L. and D.R.N. and included in the meta-analysis if the data were based on randomized, placebo-controlled studies on PGTCS, and contained efficacy evaluations expressed as change in percent seizure frequency or $\geq 50 \%$ responder rates. A neurologist (A.L.) then reviewed the selected articles and confirmed previous exclusions.

A total of 7 published trials for adjunctive therapy for PGTCS were eligible for the meta-analysis. The quality of each trial was assessed using a published instrument to evaluate the methodology and clinical relevance. ${ }^{6}$ Quality scores ranging from 0 to 1 were assigned for each trial. ${ }^{6}$ The average quality score for the 7 trials used in this analysis was 0.74 with an SD of 0.1 and range of 0.51 to 0.81 . To minimize the risk of bias across studies, all relevant data within the 7 publications were used and there was no selective reporting within studies, an approach that avoided selection bias.

\section{Effect measures, quantitative analysis, and statistical methods}

The most commonly reported efficacy measures in the selected trials were median percent reduction in seizure frequency from baseline and responder rate, defined as a $\geq 50 \%$ reduction in seizure frequency from baseline. Data from these 2 efficacy measures were extracted from the selected trials for participant groups receiving adjunctive drug treatment or placebo. Forest plots were constructed and standardized mean differences (SMD) between drug and placebo groups, SE of SMD, odds ratios (ORs), risk ratios, and $95 \%$ confidence intervals (CIs) for each trial were calculated to determine the relative strength of the baseline-subtracted efficacy measures in pediatric and adult populations using the 
Comprehensive Meta-Analysis V3.0 statistical analysis package for research synthesis.

As the SD of the measure of effect was not available for all studies, it was estimated using CIs from the French et al. ${ }^{7}$ perampanel study (FYCOMPA; Eisai, Inc., Woodcliff Lake, $\mathrm{NJ})$ as follows. An estimated SD was obtained as $([0.3 / 2] \times$ $\sqrt{[81]}) / 1.96=0.69$, based on the $95 \%$ CI for median difference of percent change of $15 \%-45 \%$ and sample size of 81 participants per treatment group in the French et al. ${ }^{7}$ study. This estimated SD (0.69) was used as a common SD across the PGTCS trials. The analysis was further supported by sensitivity analyses, assuming SD values between 0.69 and 1.06 .

A conservative estimate of common $\mathrm{SD}=1.06$ was derived as follows. From the French et al. study, ${ }^{7}$ difference in median between the drug and placebo groups was 0.381 and $n=81$ in both treatment groups. Based on the confidence bound for the difference of $(0.15,0.45)$, larger distance between half distance of the 2 confidence limits $(0.45-0.15) / 2$ and the difference between the median and lower limit (0.381-0.15) is $1.96 \mathrm{SE}$ of median difference. The maximum $\mathrm{SD}$ is given by $(0.381-0.15)=1.96 \times(\mathrm{SD} / \sqrt{[81]})$. Therefore, $\mathrm{SD}=$ $(0.381-0.15) \times(9 / 1.96)=1.06$ is a conservative estimate for the common SD.

Figure 1 Identification of clinical trials in adults and children 2-12 years of age with primary generalized tonic-clonic seizures

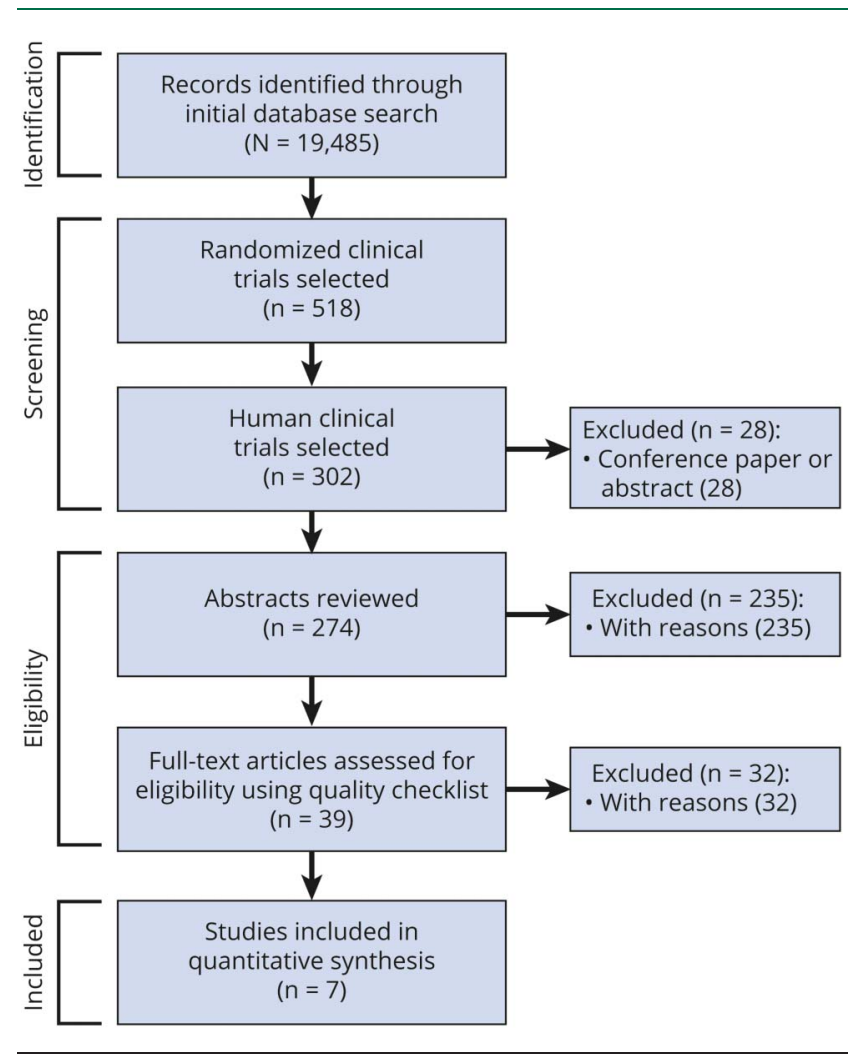

This SD was then used to calculate the SE of the SMD as follows:

$$
\mathrm{SE}=\sqrt{\frac{\mathrm{n}_{1}+\mathrm{n}_{2}}{\mathrm{n}_{1} \mathrm{n}_{2}}+\frac{(\text { std.diff })^{2}}{2\left(\mathrm{n}_{1}+\mathrm{n}_{2}\right)}}
$$

\section{Results}

\section{Age 2-12 years and comparable adolescent and adult trials}

Characteristics of the 7 trials eligible for quantitative analysis in adolescents and adults and children 2-12 years of age are shown in table 1 (with references), and summaries of the individual trials are detailed in text e-2 (doi.org/10.5061/ dryad.cg24gt6). All trials were for the treatment of PGTCS (4 lamotrigine [LTG], 1 perampanel, and 2 topiramate [TPM]), with 2 trials conducted in adults, 2 trials in adults and adolescents (12-16 years of age), 2 trials in adults and children, and 1 trial in adolescents and children (2-12 years of age).

\section{Adjunctive therapy for PGTCS}

The changes in median percent seizure reduction in each study group are summarized in table 2 for LTG, perampanel, and TPM. The baseline-subtracted measures of effect based on median percent seizure reduction in trials conducted in adults and children were comparable for adjunctive therapy of PGTCS with LTG and TPM (figure e-1, A and B, doi.org/10. 5061/dryad.cg24gt6). The participants in the perampanel study were adults and adolescents ( 12 years and older) and there was no pediatric group for comparison.

Forest plots were created and the standard difference between drug and placebo groups and their corresponding 95\% CIs were calculated for each trial and patient subgroup to evaluate the percent reduction in seizure frequency between adults and children from the 7 studies. Figure 2 presents an efficacy comparison between treatment groups for median percent reduction in seizure frequency from baseline and for $\geq 50 \%$ responder rate from baseline. The percent reduction in seizure frequency from baseline results for the standard difference and its 95\% CI are summarized for each trial in figure e-1A (doi.org/10.5061/ dryad.cg24gt6). The fixed-effect model in figure e-1B (doi.org/ $10.5061 /$ dryad.cg24gt6) shows the differences in reduction in PGTCS frequency from baseline by patient subgroup. The baseline-subtracted standard difference in the median percent reduction in PGTCS frequency was similar between adults and children within the same drug group as well as across different drug groups (figure e-2, doi.org/10.5061/dryad.cg24gt6). The drug group was consistently favored over placebo. Furthermore, lower 95\% CI bounds were above 0 for children in the doubleblind phase and near 0 for the maintenance phase, with significant overlap with the adult confidence bounds for both phases (figure e-1B, doi.org/10.5061/dryad.cg24gt6).

$\mathrm{LTG}^{8}$ and $\mathrm{TPM}^{9}$ trials were the only eligible studies with data that could be separated by age group to compare children $<12$ 
Table 1 Characteristics of studies among adolescents and adults and children 2-12 years of age with primary generalized tonic-clonic seizures

\begin{tabular}{|c|c|c|c|c|}
\hline Study & Participants & Study design & Daily dosage of active treatment & No. (ITT or non-ITT) \\
\hline \multicolumn{5}{|l|}{ Lamotrigine } \\
\hline Biton et al., $2010^{a, 14}$ & Adults, adolescents ${ }^{\mathrm{b}}$ & PG & Varied $^{c}$ & 143 \\
\hline Biton et al., $2005^{8}$ & Adults, children & PG & Varied $^{\mathrm{c}}$ & 117 \\
\hline Ettinger et al., $2007^{15}$ & Adults & PG & Varied $^{c}$ & $70^{\mathrm{a}}$ \\
\hline Trevathan et al., $2006^{16}$ & Adolescents, children ${ }^{d}$ & PG & Varied $^{c}$ & 45 \\
\hline \multicolumn{5}{|l|}{ Perampanel } \\
\hline French et al., $2015^{7}$ & Adults, adolescents & PG & $8 \mathrm{mg}^{\mathrm{e}}$ & 162 \\
\hline \multicolumn{5}{|l|}{ Topiramate } \\
\hline Biton et al., $1999^{9}$ & Adults, children & PG & $6 \mathrm{mg} / \mathrm{kg}^{\mathrm{f}}$ & $80^{\mathrm{a}}$ \\
\hline Biton et al., $2005^{17}$ & Adults & PG & $400 \mathrm{mg}$ & $22^{\mathrm{a}}$ \\
\hline \multicolumn{5}{|c|}{$\begin{array}{l}\text { Abbreviations: ITT = intention to treat; PG = parallel group. } \\
\text { a Study using extended-release lamotrigine. } \\
\text { b Adolescents in this study were } 13 \text { years and older. } \\
\text { c Dosing varied depending on concomitant treatment and phase of study. } \\
\text { d Participants in this study were } 2-19 \text { years of age. } \\
\text { e The majority of participants ( } 80.2 \% \text { ) took perampanel } 8 \mathrm{mg}(19.8 \% \text { took } 4-8 \mathrm{mg}) \text {. } \\
\text { f Approximate dosing and exact dosing varied according to weight. }\end{array}$} \\
\hline
\end{tabular}

years of age with adolescents and adults. When separate analyses were conducted for the children (2-12 years of age for the LTG study and 4-16 years of age for the TPM study) and adult age groups, similar percentages of participants in each age group experienced reductions in seizure frequency compared with placebo. These effect measures ranged from $50.0 \%$ to $79.7 \%$ in children and $57.0 \%$ to $64.0 \%$ in adults (table 2). Due to limited sample size, statistical data were unavailable for studies separable by age group.

The baseline-subtracted effect measures based on the responder rate of $\geq 50 \%$ reduction in seizure frequency in trials conducted in adults and children were comparable for adjunctive therapy of PGTCS with LTG and TPM (figure 2 and figure e-1, C and D, doi.org/10.5061/dryad.cg24gt6; table 3). Only 1 TPM study ${ }^{9}$ provided data separable by age group for this efficacy measure. The children (4-16 years of age) in the TPM group had a responder rate of $50 \%$ while the adults in the TPM group had a responder rate of $58 \%$ compared with $12 \%$ and $28 \%$ in their respective placebo groups. Although statistical significance was not provided due to small sample sizes, this TPM study suggested that the reduction in seizure frequency and the responder rate of $\geq 50 \%$ reduction in seizure frequency was similar across age groups.

The confidence bounds across clinical trials for $\geq 50 \%$ responder rate in seizure frequency were comparable between adults and children. The proportional analysis of $\geq 50 \%$ responder rates based on risk ratio and OR by study, and estimated risk ratio by patient subgroup, are presented in figure 2 , figure e-1C, figure e-3, and figure e-1D (doi.org/10.5061/ dryad.cg24gt6), respectively. The efficacy comparisons of estimated OR for $\geq 50 \%$ responder rate by patient subgroup are shown in figure e-4 (doi.org/10.5061/dryad.cg24gt6). Figures e-1C and e-3 (doi.org/10.5061/dryad.cg24gt6) show the estimated risk ratios and ORs between drug group and placebo group from the $\geq 50 \%$ responder rates in the pediatric population. These were consistently in favor of the drug group across trials and were very similar to the $\geq 50 \%$ responder rates seen in the adult population. Furthermore, the estimated risk ratios for each patient subgroup in figure e-1D (doi.org/10. 5061/dryad.cg24gt6) are comparable among the adult, adult plus children, and children subgroups in these studies, as evidenced by overlapping CIs. The wide 95\% CI for the children subgroup is due to small sample size ( $\mathrm{n}=8$ for the drug group and $n=12$ for the placebo group).

Sensitivity analyses for median percent change in reduction of seizure frequency related to the assumption of common SD further demonstrate similar results across studies in the adult, adult plus children, and children subgroups using $3 \mathrm{SD}$ values between 0.69 and 1.06 (figures e-5, 6, and 7, doi.org/10.5061/ dryad.cg24gt6). An additional sensitivity analysis was conducted, as shown in figure e-8 (doi.org/10.5061/dryad. cg24gt6), by fixing the extent of variability in relation to the means (fixed coefficient of variation). In other words, for a standard difference of 0.552 , the variability was allowed to change according to the treatment difference. This sensitivity analysis showed significant overlap in the $95 \%$ CIs between studies in adult, adult plus children, and children subgroups, suggesting that differences based on median percent change in reduction of PGTCS frequency between drug and placebo were similar in adults and children. 
Table 2 Median percent seizure reduction between baseline and treatment periods by drug for adults and children 2-12 years of age with primary generalized tonic-clonic seizures

\begin{tabular}{|c|c|c|c|c|c|c|c|c|}
\hline \multirow[b]{2}{*}{ Drug } & \multirow[b]{2}{*}{ Study } & \multirow[b]{2}{*}{ Study group within study } & \multirow[b]{2}{*}{ Phase } & \multicolumn{2}{|l|}{ Drug } & \multicolumn{2}{|l|}{ Placebo } & \multirow[b]{2}{*}{$p$ Value } \\
\hline & & & & Median, \% & No. & Median & No. & \\
\hline LTG XR & Biton et al., $2010^{14}$ & Adult ( $\geq 13$ years) & $E, M$ & 75.4 & 69 & 32.1 & 72 & $<0.0001$ \\
\hline LTG XR & Biton et al., $2010^{14}$ & Adult ( $\geq 13$ years) & M & 89.7 & 68 & 33.3 & 70 & $<0.0001$ \\
\hline LTG XR & Biton et al., $2010^{14}$ & Adult ( $\geq 13$ years) & E & 61.9 & 69 & 30.6 & 72 & 0.0016 \\
\hline LTG & Biton et al., $2005^{8}$ & Adult, children (2-12 years) & $E, M$ & 66.5 & 58 & 34.2 & 59 & 0.006 \\
\hline LTG & Biton et al., $2005^{8}$ & Adult, children (2-12 years) & M & 81.9 & 54 & 43.0 & 52 & $<0.05$ \\
\hline LTG & Biton et al., $2005^{8}$ & Adult, children ( $2-12$ years) & $\mathrm{E}$ & 60.6 & 58 & 32.8 & 59 & $<0.05$ \\
\hline LTG & Biton et al., $2005^{8}$ & Children (2-12 years) & $E, M$ & 79.7 & 12 & 43.5 & 11 & NR \\
\hline LTG & Biton et al., $2005^{8}$ & Adult (>12 years) & $E, M$ & 64.0 & 46 & 28.6 & 48 & NR \\
\hline LTG & Ettinger et al., $2007^{15}$ & Adult ( $\geq 16$ years) & $E, M$ & 66.5 & 32 & 33.0 & 38 & $<0.05$ \\
\hline LTG & Ettinger et al., $2007^{15}$ & Adult ( $\geq 16$ years) & M & 84.2 & 32 & 56.0 & 38 & $<0.05$ \\
\hline LTG & Ettinger et al., $2007^{15}$ & Adult ( $\geq 16$ years) & $\mathrm{E}$ & 67.3 & 32 & 34.8 & 38 & $<0.05$ \\
\hline LTG & Trevathan et al., $2006^{16}$ & Children, adolescent (2-19 years) & $\mathrm{E}, \mathrm{M}$ & 77.0 & 21 & 40.0 & 24 & 0.044 \\
\hline LTG & Trevathan et al., $2006^{16}$ & Children, adolescent (2-19 years) & M & 83.0 & 21 & 42.0 & 24 & 0.058 \\
\hline LTG & Trevathan et al., $2006^{16}$ & Children, adolescent (2-19 years) & E & 72.0 & 21 & 30.0 & 24 & 0.059 \\
\hline Perampanel & French et al., $2015^{7}$ & Adult ( $\geq 12$ years) & M & 76.5 & 81 & 38.4 & 81 & $<0.0001$ \\
\hline TPM & Biton et al., $1999^{9}$ & Adult, children (4-16 years) & $\mathrm{DB}$ & 56.7 & 30 & 9.0 & 40 & 0.019 \\
\hline TPM & Biton et al., $1999^{9}$ & Adult (>16 years) & ITT & 57.0 & 31 & 25.0 & 28 & NR \\
\hline TPM & Biton et al., $1999^{9}$ & Children (4-16 years) & $\mathrm{ITT}$ & 50.0 & 8 & 4.0 & 12 & NR \\
\hline TPM & Biton et al., $2005^{17}$ & Adult & T & 64.0 & 11 & 38.0 & 11 & $>0.05$ \\
\hline
\end{tabular}

Abbreviations: $\mathrm{DB}=$ double-blind phase; $\mathrm{E}=$ escalation phase; ITT = intention to treat; $\mathrm{LTG}=$ lamotrigine; $\mathrm{M}=$ maintenance phase; $\mathrm{NR}=$ not reported; $\mathrm{T}=$ treatment phase; TPM = topiramate; $\mathrm{XR}=$ extended release.

\section{Discussion}

It is difficult to perform randomized, placebo-controlled addon trials in children with antiseizure drugs that are already approved for use in adults. Concerns have been raised about young children potentially being randomized to receive addon placebo, thereby continuing to experience life-threatening seizures for many months, rather than seeking effective available therapy. There is an urgent need to provide safety and pharmacokinetics data in younger children, while protecting them from possibly unnecessary trials to redemonstrate efficacy that has already been demonstrated for the same seizure type in adults.

This meta-analysis was conducted in response to a regulatory request for perampanel, for which published data on efficacy in individuals with primary generalized tonic-clonic seizures only exist for patients aged $\geq 12$ years. ${ }^{7}$ From our extensive literature review, we found that lamotrigine and topiramate trials were the only eligible studies that could be separated by age to compare children aged $\leq 12$ years with adolescents and adults aged $>12$ years. We did not find any substantial differences in the reported efficacy of the administered drugs between children and adults in 7 clinical trials, measured either by median percent reduction in seizure frequency from baseline or $\geq 50 \%$ responder rate. Although the number of clinical trials for PGTCS that met the criteria for this meta-analysis was limited, the findings presented are based on efficacy measures from well-controlled trials, most of which were conducted in both adults and children, across 3 different antiseizure drugs. One small difference was noted in the subgroup analyses, where a larger range for SMD and wider 95\% CIs were observed for children in both the double-blind and maintenance phases compared with adults. This was also observed for risk ratios and $\geq 50 \%$ responder rates. The reason for this wider range is not known but possibilities include the smaller sample size or greater degree of variability within the pediatric population.

These results do not offer any evidence to suggest key differences in the efficacy of antiseizure drugs against PGTCS in 


Age subgroup
Adult DB ${ }^{15}$
Adult DB $(>12)^{8}$
Adult DB $(\geq 13)^{14}$
Adult M $^{15}$
Adult M $(\geq 13)^{14}$
Both DB $(\geq 2)^{8}$
Both M $(\geq 2)^{8}$
Children DB $(2-20)^{16}$
Children DB $(2-12)^{8}$
Children M $(2-20)^{16}$
Adult DB
Adult DB $(>16)^{9}$
Both DB $(\geq 2)^{9}$
Children DB $(4-16)^{9}$
Adult M $(\geq 12)^{7}$

Mean difference and $95 \% \mathrm{Cl}$ in median \% reduction of PGTC seizure frequency (by study group)

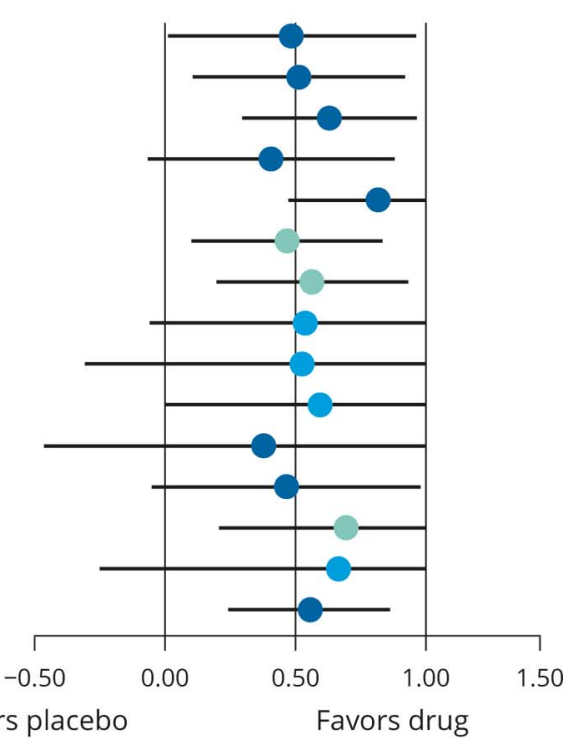

0.1 Adult Children Both

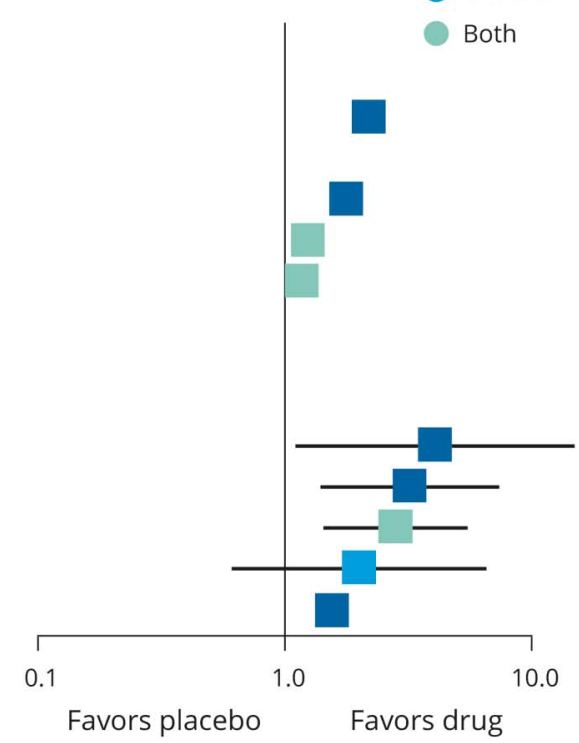

Estimated risk ratios and $95 \% \mathrm{Cl}$ in $\geq 50 \%$ responder rate (by study group)

$\mathrm{Cl}=$ confidence interval; $\mathrm{DB}=$ double-blind phase; $\mathrm{M}$ = maintenance phase; $\mathrm{PGTC}=$ primary generalized tonic-clonic.

adults and children. The lack of any signal to suggest a substantial difference bolsters the argument that efficacy data of antiseizure drugs in adults could be extrapolated to children aged 2 years and older. This argument is identical to the one recently advanced for arguing disease similarity for FOS between children and adults. ${ }^{5}$ Unlike in that study, which was performed under the auspices of a Food and Drug Administration partnership, individual pharmacokinetics/ pharmacodynamics assessments were not available for our study.

Table 3 Proportion of participants with $\geq 50 \%$ reduction in seizure frequency between baseline and treatment periods by drug for adults and children 2-12 years of age with primary generalized tonic-clonic seizures

\begin{tabular}{|c|c|c|c|c|c|c|c|c|}
\hline \multirow[b]{2}{*}{ Drug } & \multirow[b]{2}{*}{ Study } & \multirow[b]{2}{*}{ Study group within study } & \multirow[b]{2}{*}{ Phase } & \multicolumn{2}{|l|}{ Drug } & \multicolumn{2}{|l|}{ Placebo } & \multirow[b]{2}{*}{$p$ Value } \\
\hline & & & & Median, \% & No. & Median & No. & \\
\hline LTG XR & Biton et al., $2010^{14}$ & Adult ( $\geq 13$ years) & $\mathrm{E}, \mathrm{M}$ & 69.6 & 69 & 31.9 & 72 & $<0.0001$ \\
\hline LTG XR & Biton et al., $2010^{14}$ & Adult ( $\geq 13$ years) & M & 75.0 & 68 & 41.4 & 70 & $<0.0001$ \\
\hline LTG XR & Biton et al., $2010^{14}$ & Adult ( $\geq 13$ years) & $\mathrm{E}$ & 55.1 & 69 & 31.9 & 72 & 0.0067 \\
\hline LTG & Biton et al., $2005^{8}$ & Adult, children (2-12 years) & $\mathrm{E}, \mathrm{M}$ & 64.0 & 58 & 39.0 & 59 & $<0.05$ \\
\hline LTG & Biton et al., $2005^{8}$ & Adult, children (2-12 years) & M & 72.0 & 58 & 49.0 & 59 & $<0.05$ \\
\hline Perampanel & French et al., $2015^{7}$ & Adult ( $\geq 12$ years) & M & 64.2 & 81 & 39.5 & 81 & 0.0019 \\
\hline TPM & Biton et al., $1999^{9}$ & Adult, children (4-16 years) & ITT & 56.0 & 39 & 20.0 & 40 & 0.001 \\
\hline TPM & Biton et al., $1999^{9}$ & Adult (>16 years) & ITT & 58.0 & 31 & 18.0 & 28 & NR \\
\hline TPM & Biton et al., $1999^{9}$ & Children (4-16 years) & $\mathrm{ITT}$ & 50.0 & 8 & 25.0 & 12 & NR \\
\hline TPM & Biton et al., $1999^{9}$ & Adult, children (4-16 years) & DB & 62.0 & 34 & 19.0 & 37 & $<0.001$ \\
\hline TPM & Biton et al., $2005^{17}$ & Adult & $\mathrm{T}$ & 73.0 & 11 & 18.0 & 11 & 0.03 \\
\hline
\end{tabular}

Abbreviations: $\mathrm{DB}=$ double-blind phase; $\mathrm{E}=$ escalation phase; $\mathrm{ITT}=$ intention to treat; $\mathrm{LTG}=$ lamotrigine; $\mathrm{M}=$ maintenance phase; $\mathrm{NR}=$ not reported; $\mathrm{T}=$ treatment phase; TPM = topiramate; $X R=$ extended release. 
These results are not surprising since, from a clinical and electrophysiologic standpoint, the authors are unaware of any significant differences between PGTCS seen in children with idiopathic epilepsies and those in adults. PGTCS are rare before 2 years of age, ${ }^{10}$ but after this age they appear with similar semiology to adults. ${ }^{10}$ Thalamocortical projections that are integral in the production of PGTCS are fully functional by 2 years of age, and this is clearly evidenced by the appearance of normal physiologic waveforms such as synchronized sleep spindles, vertex waves, and K-complexes. ${ }^{11,12}$ Furthermore, generalized spike-wave discharges, an important interictal feature seen in patients with PGTCS, are present by 2 years of age. ${ }^{13}$

Limitations of this analysis include the paucity of trials with data that could be separated by age group, differences in clinical trial methodology and reporting of results, variability in the subject population, differences in analysis subsets, and varying length of treatment phases and dosage. In addition, this meta-analysis was restricted to efficacy measures. It is important to highlight that there may be significant differences in tolerance, side effects, and pharmacokinetics between adults and children treated with antiseizure drugs for PGTCS. Therefore, these measures should be independently studied to provide useful information for clinicians caring for children with PGTCS.

This analysis supports the similarity of efficacy data from antiseizure drug clinical trials for PGTCS in adults to children 2-12 years of age. This evidence, along with an understanding that PGTCS are similar in adult and pediatric patients with idiopathic (genetic) generalized epilepsies, supports the extrapolation of current labeling to pediatric patients for efficacy measurements. Pharmacokinetics and safety data were not addressed in this analysis, and remain important domains for study within the pediatric population.

\section{Acknowledgment} $\mathrm{NJ}$, for reviewing the manuscript. Editorial support, under the direction of the authors, was provided by Adele Blair, $\mathrm{PhD}$, of CMC AFFINITY, a division of McCann Health Medical Communications Ltd., Glasgow, UK, funded by Eisai Inc., in accordance with Good Publication Practice (GPP3) guidelines.

\section{Study funding}

The analyses presented here were funded by Eisai Inc.

\section{Disclosure}

D. Nordli is an Associate Editor for UpToDate and has served as an advisor for Eisai. E. Bagiella has served as an advisor for Eisai Inc. A. Arzimanoglou occasionally serves as an advisory board member, consultant, or lecturer for Eisai, GW Pharmaceuticals, Shire, Takeda, UCB Pharma, and Zogenix, and has received royalties. $\mathrm{He}$ or his institution also received research grants from Caixa Bank Foundation, the European Commission, and UCB Pharma. J. Wang is an employee of Eisai Inc. D. Kumar is an employee of Eisai Inc. A. Laurenza was formerly an employee of Eisai Inc. J. French receives NYU salary support
The authors thank Leock Y. Ngo of Eisai Inc., Woodcliff Lake,

from the Epilepsy Foundation and for consulting work and/or attending Scientific Advisory Boards on behalf of the Epilepsy Study Consortium for Acadia, Adamas, Addex, Aeonian, Alexza, Anavex, Axcella Health, Axovant, Biogen, Biomotiv/ Koutif, Blackfynn, Bloom Science, Bridge Valley Ventures, Cavion, Cerebral Therapeutics, Cerevel, Clinilabs, Concert Pharmaceuticals, Covance, CuroNZ, Eisai, Empatica, Engage Therapeutics, Epitel, GW Pharmaceuticals, Idorsia, Impax, Ionis, J\&J Pharmaceuticals, Marinus, MonosolRx, Neurelis, Novartis, Otsuka Pharmaceutical Development, Ovid Therapeutics Inc., Pfizer, Pfizer-Neusentis, Redpin, Sage, Sancillio, Shire, SK Life Science, Springworks, Stoke, Sunovion, Supernus, Takeda, UCB Inc., Ultragenyx, Upsher-Smith, Vyera, West Therapeutic Development, Xenon, Xeris, Zogenix, and Zynerba. J. French has also received research grants from Biogen, Cavion, Engage, Neurelis, Ovid, SK Life Science, UCB Pharma, and Zogenix, as well as grants from the Epilepsy Research Foundation, the Epilepsy Study Consortium, and National Institute of Neurological Disorders and Stroke. She is on the editorial board of Lancet Neurology and Neurology Today. She is scientific officer for the Epilepsy Foundation, for which NYU receives salary support. She has received travel reimbursement related to research, advisory meetings, or presentation of results at scientific meetings from the Epilepsy Study Consortium, the Epilepsy Foundation, Adamas, Axovant, Biogen, Blackfynn, CuroNz, Eisai, Engage, Idorsia, Neurelis, Novartis, Otsuka, Ovid, Pfizer, Redpin, Sage, SK Life Science, Sunovion, Takeda, UCB Pharma, Ultragenyx, and Zynerba. Go to Neurology.org/N for full disclosures.

\section{Publication history}

Received by Neurology March 7, 2019. Accepted in final form November 20, 2019.

Appendix Authors

\begin{tabular}{|c|c|c|}
\hline Name & Location & Contribution \\
\hline $\begin{array}{l}\text { Douglas R. } \\
\text { Nordli, Jr., MD }\end{array}$ & University of Chicago, IL & $\begin{array}{l}\text { Contributed to the review } \\
\text { of published papers, } \\
\text { analysis of the data, and } \\
\text { writing of the manuscript }\end{array}$ \\
\hline $\begin{array}{l}\text { Emilia Bagiella, } \\
\text { PhD }\end{array}$ & $\begin{array}{l}\text { Mount Sinai School of } \\
\text { Medicine, New York, NY }\end{array}$ & $\begin{array}{l}\text { Contributed to the } \\
\text { analysis of the data and } \\
\text { interpretation and the } \\
\text { writing and review of the } \\
\text { manuscript }\end{array}$ \\
\hline $\begin{array}{l}\text { Alexis } \\
\text { Arzimanoglou, } \\
\text { MD }\end{array}$ & $\begin{array}{l}\text { Department of Pediatric } \\
\text { Clinical Epileptology, } \\
\text { Sleep Disorders and } \\
\text { Functional Neurology, } \\
\text { University Hospitals of } \\
\text { Lyon (HCL), Member of } \\
\text { the European Reference } \\
\text { Network EpiCARE, Lyon, } \\
\text { France; research } \\
\text { coordinator, Paediatric } \\
\text { Epilepsy Unit, Hospital } \\
\text { Sant Joan de Déu, } \\
\text { Member of the European } \\
\text { Reference Network } \\
\text { EpiCARE and Universitat } \\
\text { de Barcelona, Spain }\end{array}$ & $\begin{array}{l}\text { Contributed to the } \\
\text { conception of the study, } \\
\text { analysis of the data, and } \\
\text { writing and review of the } \\
\text { manuscript }\end{array}$ \\
\hline
\end{tabular}


Appendix (continued)

\begin{tabular}{|c|c|c|}
\hline Name & Location & Contribution \\
\hline $\begin{array}{l}\text { Jinping Wang, } \\
\text { PhD }\end{array}$ & $\begin{array}{l}\text { Eisai Inc., Woodcliff Lake, } \\
\text { NJ }\end{array}$ & $\begin{array}{l}\text { Contributed by reviewing } \\
\text { and screening the } \\
\text { abstracts for full article } \\
\text { review and reviewing and } \\
\text { selecting the full articles } \\
\text { for quantitative analysis } \\
\text { and extracted the data for } \\
\text { meta-analysis }\end{array}$ \\
\hline $\begin{array}{l}\text { Dinesh Kumar, } \\
\text { PhD }\end{array}$ & $\begin{array}{l}\text { Eisai Inc., Woodcliff Lake, } \\
\text { NJ }\end{array}$ & $\begin{array}{l}\text { Contributed to the } \\
\text { analysis of the data, } \\
\text { writing and review of the } \\
\text { manuscript, conception } \\
\text { of the study, analysis of } \\
\text { the data, and writing and } \\
\text { review of the manuscript }\end{array}$ \\
\hline $\begin{array}{l}\text { Antonio } \\
\text { Laurenza, MD }\end{array}$ & $\begin{array}{l}\text { Formerly of Eisai Inc., } \\
\text { Woodcliff Lake, NJ }\end{array}$ & $\begin{array}{l}\text { Contributed to the } \\
\text { conception of the study, } \\
\text { analysis of the data, and } \\
\text { writing and review of the } \\
\text { manuscript }\end{array}$ \\
\hline $\begin{array}{l}\text { Jacqueline } \\
\text { French, MD }\end{array}$ & $\begin{array}{l}\text { NYU Comprehensive } \\
\text { Epilepsy Center, New } \\
\text { York, NY }\end{array}$ & $\begin{array}{l}\text { Contributed to the } \\
\text { conception of the study, } \\
\text { analysis of the data, and } \\
\text { writing and review of the } \\
\text { manuscript }\end{array}$ \\
\hline
\end{tabular}

\section{References}

1. Devinsky O. Sudden, unexpected death in epilepsy. N Engl J Med 2011;365: 1801-1811.

2. Epilepsy Foundation. Tonic-Clonic Seizures [online]. 2017. Available at: epilepsy. com/learn/types-seizures/tonic-clonic-seizures. Accessed August 02, 2019.
3. Chiron C, Dulac O, Pons G. Antiepileptic drug development in children: considerations for a revisited strategy. Drugs 2008;68:17-25.

4. Food and Drug Administration, US Department of Health and Human Services, Center for Drug Evaluation and Research (CDER). Drugs for treatment of partial onset seizures: full extrapolation of efficacy from adults to pediatric patients 4 years of age and older. Guidance for industry [online]. 2018. Available at: fda.gov/ucm/ groups/fdagov-public/@fdagov-drugs-gen/documents/document/ucm596731.pdf. Accessed August 02, 2019.

5. Pellock JM, Arzimanoglou A, D'Cruz O, et al. Extrapolating evidence of antiepileptic drug efficacy in adults to children $>/=2$ years of age with focal seizures: the case for disease similarity. Epilepsia 2017;58:1686-1696.

6. Cho MK, Bero LA. Instruments for assessing the quality of drug studies published in the medical literature. JAMA 1994;272:101-104.

7. French JA, Krauss GL, Wechsler RT, et al. Perampanel for tonic-clonic seizures in idiopathic generalized epilepsy: a randomized trial. Neurology 2015;85:950-957.

8. Biton V, Sackellares JC, Vuong A, Hammer AE, Barrett PS, Messenheimer JA. Double-blind, placebo-controlled study of lamotrigine in primary generalized tonicclonic seizures. Neurology 2005;65:1737-1743.

9. Biton V, Montouris GD, Ritter F, et al. A randomized, placebo-controlled study of topiramate in primary generalized tonic-clonic seizures: Topiramate YTC Study Group. Neurology 1999;52:1330-1337.

10. Korff C, Nordli DR Jr. Do generalized tonic-clonic seizures in infancy exist? Neurology 2005;65:1750-1753.

11. Toulmin H, Beckmann CF, O'Muircheartaigh J, et al. Specialization and integration of functional thalamocortical connectivity in the human infant. Proc Natl Acad Sci USA 2015;112:6485-6490.

12. Clawson BC, Durkin J, Aton SJ. Form and function of sleep spindles across the lifespan. Neural Plast 2016;2016:6936381.

13. Caraballo RH, Darra F, Fontana E, Garcia R, Monese E, Dalla Bernardina B. Absence seizures in the first 3 years of life: an electroclinical study of 46 cases. Epilepsia 2011 52:393-400.

14. Biton V, Di Memmo J, Shukla R, et al. Adjunctive lamotrigine XR for primary generalized tonic-clonic seizures in a randomized, placebo-controlled study. Epilepsy Behav 2010;19:352-358

15. Ettinger $A B$, Kustra RP, Hammer AE. Effect of lamotrigine on depressive symptoms in adult patients with epilepsy. Epilepsy Behav 2007;10:148-154.

16. Trevathan E, Kerls SP, Hammer AE, Vuong A, Messenheimer JA. Lamotrigine adjunctive therapy among children and adolescents with primary generalized tonic clonic seizures. Pediatrics 2006;118:e371-e378.

17. Biton V, Bourgeois BF; YTC/YTCE Study Investigators. Topiramate in patients with juvenile myoclonic epilepsy. Arch Neurol 2005;62:1705-1708. 


\section{Neurology}

\section{Meta-analysis of drug efficacy in adult vs pediatric trials of patients with PGTC seizures}

Douglas R. Nordli, Jr, Emilia Bagiella, Alexis Arzimanoglou, et al.

Neurology 2020;94;e1845-e1852 Published Online before print April 1, 2020

DOI 10.1212/WNL.0000000000009325

This information is current as of April 1, 2020

\section{Updated Information \& Services}

\section{References}

Subspecialty Collections

Permissions \& Licensing

Reprints including high resolution figures, can be found at: http://n.neurology.org/content/94/17/e1845.full

This article cites 15 articles, 5 of which you can access for free at: http://n.neurology.org/content/94/17/e1845.full\#ref-list-1

This article, along with others on similar topics, appears in the following collection(s):

All Epilepsy/Seizures

http://n.neurology.org/cgi/collection/all_epilepsy_seizures

All Pediatric

http://n.neurology.org/cgi/collection/all_pediatric

Antiepileptic drugs

http://n.neurology.org/cgi/collection/antiepileptic_drugs

Clinical trials Systematic review/meta analysis

http://n.neurology.org/cgi/collection/clinical_trials_systematic_review_ meta_analysis_.

Generalized seizures

http://n.neurology.org/cgi/collection/generalized_seizures

Information about reproducing this article in parts (figures,tables) or in its entirety can be found online at:

http://www.neurology.org/about/about_the_journal\#permissions

Information about ordering reprints can be found online:

http://n.neurology.org/subscribers/advertise

Neurology ${ }^{\circledR}$ is the official journal of the American Academy of Neurology. Published continuously since 1951, it is now a weekly with 48 issues per year. Copyright Copyright ( 2020 The Author(s). Published by Wolters Kluwer Health, Inc. on behalf of the American Academy of Neurology.. All rights reserved. Print ISSN: 0028-3878. Online ISSN: 1526-632X.

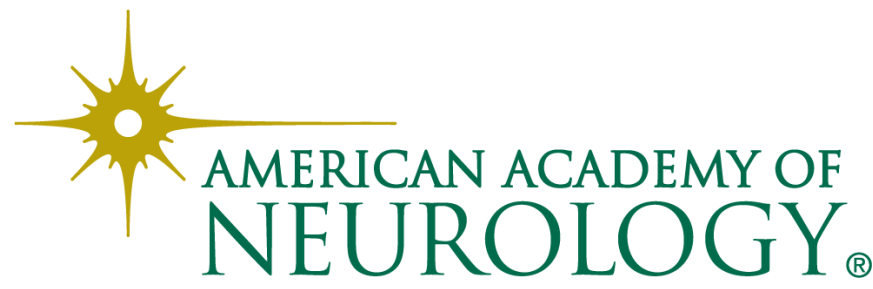

